\title{
EDITORIAL \\ EL APORTE DE LAS CIENCIAS SOCIALES Y HUMANAS DESDE LA ACADEMIA
}

El interés que muestran los investigadores por publicar sus trabajos de reflexión e investigación acrecienta el diálogo científico con el que las revistas especializadas cumplen la misión de transferir el conocimiento. En este número, la Revista Encuentros publica textos que explicitan un nuevo humanismo que se abre paso en el siglo XXI desde la construcción de las nuevas Sociedades de la Información y el Conocimiento (SIC). Se presentan a continuación textos entre los que se encuentran ensayos, análisis y reflexiones concienzudas (6), trabajos de investigación (8), nutridos de temáticas que enlazan los nuevos desafíos y retos de la SIC.

Desde el ámbito de los nuevos retos de la Sociedad de la Información y el Conocimiento se invita al lector a revisar los textos que brindan una mirada analítica y reflexiva a la formación del docente y a la asunción de nuevos roles docentes. En esta línea está el trabajo presentado por Luz Estela Gómez-Vahos, Luz Enid Muriel-Muñoz y David Alberto Londoño-Vásquez bajo un título que expresa su esencia: "El papel del docente para el logro de un aprendizaje significativo apoyado en las TIC". Los autores destacan la necesaria integración de contenidos y formación humanística en la educación para que las personas puedan "intervenir en el entorno, comprendiendo realidades locales y globales desde el pensamiento crítico y reflexivo”.

María Nay-Valero y María Elena Febres Cordero-Briceño revisan aspectos históricos, fundamentos y tendencias sobre los que debe formarse el docente del siglo XXI, destacando nuevos conceptos como son: Educación Ambiental y Educación para la Sostenibilidad. En lo disciplinar se destaca la revisión teórica y evolutiva que adelantó Jennifer Joan Fuenmayor-De Fernández en torno al pensamiento administrativo francés -antecedente de la administración pública-, hasta llegar a proyectarla como disciplina científica y situar la génesis de la ciencia de la Administración Pública en 1808.

Una mirada a la 'Historia' de Colombia y los contenidos curriculares de esta asignatura (eliminada de la educación colombiana en 1994 por el presidente César Gaviria y fusionada en el marco de las Ciencias Sociales), suscita enorme interés actual. Precisamente el texto de Nilson Javier Ibagón habla de la falta de profundidad interpretativa, crítica y propositiva en los contenidos curriculares que se refieren al tema de 'la violencia' en la educación colombiana. ¿Estaremos conminados a repetir nuestro pasado? ¿Qué estamos dispuestos a recordar, o a olvidar, los colombianos sobre el siglo XX? En 2017 se restablece la cátedra de Historia pero la narrativa sobre esta etapa tiene serias lagunas. Ibagón señala que existe una 'presencia ausente' de la narración de la violencia en Colombia.

El papel de la universidad es objeto de estudio prospectivo de Rafael Espinoza-Rodríguez y Leonor Beatriz Castrillo-Guerra, quienes se centran en la especificidad de las universidades transfronterizas para la transferencia de conocimiento e innovación tecnológica. El estudio analiza universidades de Colombia (departamentos de Cesar y La Guajira) y Venezuela (estado del Zulia) invocando la importancia de estrategias de integración que apoyen a los gobiernos de ambos países".

Los textos derivados de investigación constituyen otro bloque de igual importancia que revisa tensiones e intereses de los investigadores sobre varias de las grandes preocupaciones de la educación actual: el rendimiento académico, 


\section{Encuentros}

de un lado, y en el otro extremo, la necesidad de revisar las competencias (de investigación principalmente) como aportación y fortalecimiento que deben realizar los estudiantes. Se presentan a continuación investigaciones en el contexto escolar y universitario. En cuanto al mejoramiento de la calidad educativa se habla del rendimiento académico:

a. El lector puede consultar el análisis de las funciones ejecutivas en escolares de 7 a 14 años de Montería (Córdoba), realizado por Londoño-Ocampo, Becerra-García, Arias-Castro y Martínez-Busto.

b. O revisar las variables generadoras de repitencia y procrastinación en estudiantes de Lógica y Algoritmos I y II en la Universidad de La Amazonía realizado por Claros-Moreno, Sánchez-Lopera y Millán-Rojas.

\section{En cuanto a las Competencias:}

a. Sandra Oquendo encuentra una relación directa entre los vacíos en la formación en investigación de los docentes y la poca réplica de estos procesos en la enseñanza. Señala la importancia del desarrollo de la competencia de investigación y la necesidad de crear una metodología que permita la participación y que los estudiantes investiguen de manera colaborativa

b. En el ámbito universitario Jessica Fernanda Bello-C y Janneth Arley Palacios Chavarro realizaron un estudio sobre las competencias profesionales de mayor importancia y aplicabilidad para el publicista en Bogotá, encontrando que los programas que ofrecen las IES tienen perfiles y competencias acordes con lo que el ámbito laboral está requiriendo. No obstante, cuestionan que el empleador considere al publicista, no un ejecutor de tareas, "sino un profesional con capacidades estratégicas, holísticas, de pensamiento crítico y complejo que aporta de manera significativa y positiva a transformar su realidad y contexto".

Dentro de este nuevo humanismo se exponen tres propuestas de modelos aplicables de sociedad educativa como la definió la UNESCO en el Informe Delors, 1998, "La educación encierra un tesoro:

a. José Gustavo Casas describe acciones de Estado en situaciones conflictivas bajo el título Conflictividad urbana en Chalco, desde su óptica se plantea el tema de la convivencia en México desde la observación etnográfica mostrando una problemática socio-antropológica contemporánea.

b. Tapia-Gutiérrez, Villar-Olaeta y Carrillo-Mardones afirman que: “...una vida buena en la escuela requiere prácticas de reconocimiento del otro, relaciones personales e institucionales basadas en la verdad. Se invita a articular estos sentidos para fortalecer el buen trato y la construcción de comunidad".

c. Dos textos chilenos centran su objeto de estudio en la Responsabilidad Social Empresarial: en un caso, los centros para el emprendimiento de la mujer en la región de Valparaíso; y por otro, el estudio de las empresas mineras en Chile.

Para contribuir a la difusión generalizada del conocimiento la Enseñanza Superior debe tener en cuenta: las políticas, el mundo laboral, todos los niveles del sistema educativo, la diversidad de la(s) cultura(s), la participación de todos los grupos sin exclusión, la educación a lo largo de toda la vida, los estudiantes y profesores. Si se cumple con todo ello, se garantiza la pertinencia de los sistemas de enseñanza superior (Hacia las Sociedades del Conocimiento, UNESCO, 2005, p. 106). Los textos que este volumen ofrece a la comunidad científica constituyen un abordaje selectivo con raíces en los principios de esta pertinencia educativa.

Clara Janneth Santos-Martínez

Doctora en Ciencias de la Información y la Comunicación Docente Investigador. Facultad de Ciencias Sociales y Humanas Universidad Autónoma del Caribe

DOI: 10.15665/encuent.v17i02.2119 